\title{
Comentarios de jurisprudencia de la Corte Suprema y el Tribunal Constitucional sobre derechos humanos de las personas migrantes durante el año 2013
}

\section{Jurisprudential comments on migrant's human rights made by the Supreme and Constitutional Court in 2013}

\author{
Rodrigo Godoy Araya \\ Oficina de Derechos Humanos CAJ, Chile
}

\begin{abstract}
Abogado de la Oficina Especializada en Derechos Humanos de la Corporación de Asistencia Judicial (Chile). Licenciado en Ciencias Jurídicas Universidad Católica del Norte, sede Coquimbo (Chile). Estudiante del Programa de Movilidad Internacional en Universidad de Sevilla (España). Diplomado en Estudios Internacionales por la Universidad de Chile y Diplomado en Derechos Económicos, Sociales y Culturales, Seguridad Alimentaria y Políticas Públicas por la Fundación Henry-Dunant, América Latina. Actualmente es alumno del Magíster en Derecho Internacional de los Derechos Humanos de la Universidad Diego Portales (Chile).
\end{abstract}

rgodoy@cajmetro.cl

\section{Marcel Didier von der Hundt}

Universidad Alberto Hurtado, Chile

Abogado de la Universidad Alberto Hurtado (Chile) y pasante en la Sección Refugio de la Vicaría de la Pastoral Social y de los Trabajadores, ex agencia implementadora de ACNUR en Chile. Ex postulante de la Oficina Especializada en Derechos Humanos de la Corporación de Asistencial Judicial (Chile). Actualmente se desempeña como investigador en la Clínica Jurídica de Inmigrantes de la Universidad Alberto Hurtado, en materia de derechos del niño y nacionalidad. marcel.didier.hundt@gmail.com

\section{RESUMEN}

El presente artículo tiene por objetivo comentar algunas sentencias de la Corte Suprema y del Tribunal Constitucional de Chile en materias de derecho de extranjería y derechos humanos de las personas migrantes. Para ello se estudian sentencias que han sido dictadas en casos tramitados por la Oficina Especializada en Derechos Humanos de la Corporación de Asistencia Judicial durante el año 2013, las cuales se comentan en relación a cinco ámbitos de análisis: 1) derecho a ingresar al territorio nacional; 2) expulsiones del país; 3) nacionalidad y apatridia; 4) privaciones de libertad de extranjeros en situación irregular y; 5) jurisprudencia del Tribunal Constitucional.

Palabras clave: migrantes - órdenes de expulsión y abandono - derecho a la libertad personal - derecho a la nacionalidad - apatridia.

\begin{abstract}
This article discusses both Chilean Supreme and Constitutional Court decisions regarding immigration law and migrant's human rights. For this purposes, the article analyses decisions taken in cases presents by the Oficina Especializada en Derechos Humanos de la Corporación de Asistencia Judicial in 2013, which are discussed under five different subjects: 1$)$ right to enter the national territory; 2) deportations; 3) nationality and statelessness; 4) irregular migrant's freedom restrictions; 5) Jurisprudence of the Constitutional Court.
\end{abstract}

Key words: migrant's - deportation and abandonment - right to liberty - right to nationality - statelessness. 


\section{Introducción}

En el último tiempo nos hemos encontrado con un escenario esperanzador en la evolución de la jurisprudencia nacional relativa a los derechos humanos de las personas migrantes. Esta premisa, que motiva el presente trabajo, tiene su fundamento en las sentencias dictadas por la Corte Suprema durante el año 2013 a la hora de garantizar a las personas migrantes el ejercicio de sus derechos humanos. A este proceso se suma la jurisprudencia constitucional, que recientemente se pronunció acerca del contenido y alcance del derecho a migrar, entre otras cuestiones. A partir de estos fallos, que nos entregan luces acerca del actual panorama en materia de protección de los derechos de las personas migrantes, resaltaremos las principales problemáticas que rodean a la población migrante en Chile, así como la aproximación que han adoptado las Cortes para resolver los casos que se les presentan. Los casos estudiados corresponden a acciones deducidas por la Oficina Especializada en Derechos Humanos de la Corporación de Asistencia Judicial ${ }^{1}$ (CAJ) en materia de extranjería, migración y derechos humanos.

Para satisfacer este objetivo hemos distribuido las sentencias a comentar en cinco ámbitos de análisis. El primero, dice relación con sentencias que han acogido amparos constitucionales cuando funcionarios policiales han impedido arbitrariamente el ingreso de personas extranjeras al país. El segundo, cita algunas sentencias relevantes en las que la Corte Suprema ha revocado órdenes de expulsión y/o medidas de abandono dictadas por el Ministerio del Interior contra personas extranjeras en situación irregular. En el tercer apartado, comentaremos sentencias referidas a la nacionalidad, las que ilustran la situación de los apátridas en Chile. En cuarto lugar, se abordan los casos de privaciones de libertad sin control jurisdiccional realizadas por Policía de Investigaciones contra personas migrantes con orden de expulsión. Finalmente, se comentarán los principales aspectos de la sentencia del Tribunal Constitucional sobre inaplicabilidad del Decreto Ley (D.L) No. 1094/75 (Ley de Extranjería)².

Antes de comenzar el análisis de la jurisprudencia señalada, es necesario realizar algunas aclaraciones previas respecto al marco jurídico aplicable a las personas migrantes en Chile. El D.L No. 1094/75 y su respectivo reglamento, Decreto Supremo No. 597/84², regulan el ingreso al país, la permanencia definitiva, el egreso, el reingreso, la expulsión y el control de los extranjeros. En general, estas normas otorgan amplias facultades al Ministerio del Interior para la concesión de visaciones, bajo el concepto jurídico indeterminado de "conveniencia o utilidad para el país" y describen las causales de prohibición de ingreso, que también se hacen aplicables como causales de expulsión ${ }^{4}$. Estas normas han sido destacadas por el Tribunal Constitucional como

En Chile, el derecho a la defensa se garantiza a todas las personas sin distinción. Para aquellos que no tengan los recursos económicos necesarios para ejercer dicho derecho, existe la Corporación de Asistencia Judicial, dependiente del Ministerio de Justicia, la cual se organiza y distribuye a la largo del territorio nacional por comunas o agrupaciones de comunas y según materias a conocer. Dentro de ellas, se encuentra la Oficina Especializada en Derechos Humanos, que tiene por finalidad la promoción y protección de los derechos fundamentales. En dicha Oficina se conocen materias de jurisdicción militar, solicitudes de indemnizaciones de perjuicios en contra el Estado, materias de extranjería, se solicitan beneficios penitenciarios, entre otros asuntos. En el contexto de este artículo, quisiéramos agradecer a los funcionarios y postulantes que han pasado por la Oficina de Derechos Humanos de la CAJ, quienes, con su esfuerzo y trabajo han realizado un aporte decisivo en la lucha y reivindicación de la dignidad humana de las personas migrantes en Chile.

Decreto Ley No. 1094 de 1975 que establece normas sobre extranjeros en Chile. Ministerio del Interior, República de Chile, 19 de julio de 1975. Disponible [en línea] <http://www.leychile.cl/Navegar?idNorma=6483> [consulta: 21 de abril de 2014].

Decreto Supremo No. 597 que aprueba nuevo reglamento de extranjería. Ministerio del Interior, República de Chile, 24 de noviembre de 1984. Disponible [en línea] <http://www.leychile.cl/Navegar?idNorma=14516\&idParte=\&idVersion=2000-05-23> [consulta: 21 de abril de 2014].

4 Para estos efectos revisar especialmente los artículos 13, 15, 17 y 64 del D.L. No. 1094, que determinan el alcance de las facultades del Ministerio del Interior en materia de inmigración. 
reflejo de un "esquema normativo de máxima discrecionalidad que admite masivas vulneraciones de derechos o alteraciones menores, dependientes del carácter compasivo o estricto de su invocación por las autoridades de turno" ${ }^{\prime 5}$.

\section{La persona extranjera tiene el derecho a ingresar al territorio del país}

El artículo 44 del D.L. No. 1094 señala que la autoridad puede solicitar que la persona que desea ingresar al país, acredite medios económicos suficientes previo a su ingreso. En conocimiento de un caso en que se alegaba la arbitrariedad de la negativa de permitir el ingreso a una persona, la Corte Suprema indicó que si bien existe una facultad discrecional otorgada a la autoridad, ello no significa que esta determinación quede librada al criterio (o descriterio) de los funcionarios policiales. En dicha sentencia, el máximo tribunal resolvió:

[...] para exigirle que acredite tener los medios económicos suficientes de subsistencia, tales preceptos no contemplan la forma en que ello deba ser establecido, por lo que se trata de una cuestión subjetiva y discrecional, que como tal debe ser analizada con prudencia y de forma restringida; la disposición legal no permite distinguir el origen de las sumas que traiga el extranjero, de modo que el hecho de ser obsequiadas o prestadas, no permite al funcionario policial reconducir ello a la única calificación que contempla la norma, que es su suficiencia; si la turista declara que viene invitada a la casa de una familia -circunstancia que está en condiciones de demostrar- ello es un antecedente que debe ser considerado en la apreciación de la suficiencia de los medios que trae consigo al ingresar al país; la decisión de devolver a la amparada a su país de origen apoyada en el hecho de que no portaba los medios suficientes para subsistir durante su permanencia en Chile, fue ilegal y arbitraria y vulneró la libertad de desplazamiento de la amparada, siendo ilegal también la retención de su documentación ${ }^{6}$.

Asimismo, la Corte Suprema conociendo de una acción de amparo, expresó que no cabe invocar la existencia de una medida de abandono previamente cumplida para prohibir un nuevo ingreso al país a una persona extranjera. En dicha sentencia, la Corte Suprema indicó:

[...] es claro que si un extranjero se encuentra en alguna de las hipótesis que describen los preceptos citados, se le debe denegar la entrada al país. Sin perjuicio de lo expresado, en el caso de autos y conforme a lo informado por la propia recurrida, el fundamento que se esgrime para prohibir el ingreso de la amparada no se sustenta en ninguna de las causales descritas en los preceptos citados; en consecuencia, la negativa sólo se ha fundado en la existencia de una actuación administrativa -ya agotada-, como es la resolución Exenta No. 621, de forma que no existe una impedimento real que sustente la decisión desplegada por la recurrida, decidir lo contrario implica mantener vigente en el tiempo una sanción ya cumplida; la decisión de impedir el ingreso de la amparada al país, fue ilegal y arbitraria y vulneró la libertad de desplazamiento de la amparada, puesto que no existe justificación alguna que fundamente la actuación desplegada por la autoridad recurrida, razones por las cuales el recurso interpuesto será acogido ${ }^{7}$.

Los razonamientos expuestos evidencian que la Corte Suprema estima que para que se pueda

Tribunal Constitucional. Requerimiento de inaplicabilidad por inconstitucionalidad del D.L No. 1094. Sentencia de 4 de julio de 2013. Rol 2273-2013, considerando 7.

6 Corte Suprema. Caso Grimalda Ccanccahua con Jefe de Prefectura Policial del Aeropuerto de Santiago. Sentencia de 4 de junio de 2013. Rol 3563-2013, considerando 2.

Corte Suprema. Caso Martha Riascos con Policía de Investigaciones de Chile y otros. Sentencia de 20 de junio de 2013. Rol 4014-2013, considerando 3. 
restringir el derecho a la libertad de desplazamiento, es necesario que la autoridad otorgue fundamentos razonables, lo que significa considerar los antecedentes del caso y ponderar la necesidad de satisfacer el derecho considerando los objetivos de la regulación nacional.

\section{Jurisprudencia sobre expulsiones del territorio nacional}

Cuando hablamos de orden de expulsión en la legislación chilena, nos referimos al acto administrativo a través del cual la administración del Estado dispone que una persona extranjera debe salir del territorio del país, incluso mediante coacción.

Si bien estas órdenes pueden ser impugnadas mediante los recursos administrativos ordinarios, también existe la posibilidad de deducir un recurso judicial especial contra ellas. Este recurso está contenido en el artículo 89 del citado D.L. No. 1094. En virtud de esta acción, el extranjero puede reclamar de la expulsión, en única instancia y eventualmente privado de libertad, presentando un recurso fundado ante la Corte Suprema, dentro de un plazo de 24 horas contadas desde la notificación de la expulsión. Pese a los reparos que puedan presentarse a este recurso a la luz de los estándares internacionales, especialmente en atención al acotado plazo para su interposición (lo que excede los propósitos de este trabajo), esto se ha superado a través de la utilización de la acción de amparo para impugnar las órdenes de expulsión, lo que ha sido aceptado por los tribunales superiores de justicia. Ello es de toda lógica, ya que tanto la orden de expulsión, como la dictación de una medida de abandono, importan una actuación de la autoridad que perjudica, o al menos amenaza, el derecho a la libertad ambulatoria, especialmente en los términos consagrados en el artículo 19 No. 7 letra a) de la Constitución Política de la República. De este modo, la principal fuente de jurisprudencia en materia de extranjería y migración en Chile la constituyen las sentencias dictadas por los tribunales de justicia, especialmente por la Corte Suprema, a través del conocimiento de acciones de amparo constitucional.

En este ámbito, un aspecto interesante ha sido la aplicación directa de normas de derecho internacional de derechos humanos (DIDH) al momento de resolver sobre la legalidad de las órdenes de expulsión. A ello se suma el hecho de que la Corte Suprema ha considerado las circunstancias concurrentes al evaluar la razonabilidad de las decisiones adoptadas por la administración, sean estos antecedentes familiares o, incluso, la disposición, actitud y actuaciones positivas de los amparados extranjeros en la búsqueda de una situación regular ${ }^{8}$. Como se explicará, la falta de motivación razonable o la ausencia absoluta de motivación, ha sido uno de los aspectos en que el control judicial ha sido más enérgico.

A continuación, se exponen las principales sentencias sobre expulsiones de extranjeros con vínculos de familia, especialmente de personas con hijos/as menores de edad con nacionalidad chilena. En estos casos, la Corte Suprema revoca las expulsiones dictadas contra extranjeros que habrían cometido "actos contrarios a la moral y las buenas costumbres" y realiza un test de razonabilidad y proporcionalidad de las medidas de expulsión.

\subsection{Sentencias favorables}

La Corte Suprema ha aplicado de forma directa el DIDH cuando ha resuelto casos relacionados con órdenes de expulsión de extranjeros con vínculos de familia. Más clara ha sido esta aplicación cuando hay niños/as involucrados/as. Así, en estos casos ha primado la unidad familiar y el bien superior del niño/a por sobre la necesidad del Estado de punir la irregularidad migratoria. No podemos calificar sino de acertado este criterio, constatando que a nivel de la Corte Suprema existe comprensión sobre la complejidad de la problemática migratoria, pues cuando se expulsa

Por ejemplo, cumplimiento de control de firma ante la Policía de Investigaciones, ingreso de solicitudes de visaciones ante el Departamento de Extranjería y Migración, ofertas de trabajo, entre otras. 
a un extranjero con familia, no solo se expulsa a la persona individual, sino también se disgrega el núcleo familiar, perjudicando, en la mayoría de los casos, a niños/as y adolescentes.

Ejemplos de este razonamiento lo constituyen los casos Fali Leiva con Departamento de Extranjería del Ministerio del Interior (DEM) y Luis Loyola con DEM, donde la Corte Suprema se remitió a la Convención sobre Derechos del Niño y al deber de Estado de proteger la familia. Así, en la sentencia dictada en causa de Luis Loyola, el máximo tribunal señaló:

Que por otro lado, no es posible desatender las circunstancias personales y familiares del amparado, persona que tiene una pareja estable y un hijo menor de edad de nacionalidad chilena. De manera que de ejecutarse la medida ciertamente se lesionaría el interés superior del menor, al dictaminarse una medida que implicará la separación de su padre y perturbará su identidad familiar y nacional, infringiendo los deberes que se imponen para los Estados en los artículos 3.1, 7.1, 8.1 y 9.1 de la Convención de los Derechos del Niño; y se afecta lo dispuesto en el artículo $1^{\circ}$ de la Constitución Política de la República que establece que la familia es el núcleo fundamental de la sociedad, siendo deber del Estado dar protección a la población y a la familia, así como propender al fortalecimiento de ésta. Que, en consecuencia, los fundamentos que se han invocado por la autoridad carecen de proporcionalidad en relación con la naturaleza, gravedad y ámbito de las infracciones sancionadas, y considerando la afectación que de manera irremediable producirá en su medio familiar, son motivos suficientes para revocar el fallo apelado. Por estas consideraciones y visto, además, lo dispuesto en los artículos 21 de la Constitución Política de la República, 15 №2, 17 y 71 del DL № 1094, y 3.1, 7.1, 8.1 y 9.1 de la Convención de los Derechos del Niño [...] se decide que se deja sin efecto el Decreto № 121 de 27 de enero de 2006, dictado por el Ministro del Interior, que expulsa del país al ciudadano peruano Luis Porfirio Loyola Pérez ${ }^{9}$.

\subsection{Sentencia desfavorable}

Si bien el amparo deducido en la causa de Sanji Kelemen con DEM fue rechazado por la Corte Suprema -al estimarse que se encontraba justificada su expulsión por haber cometido un delito en territorio nacional- consideramos de interés mencionar y reproducir parte del voto del Ministro Carlos Cerda, quien, ante la disyuntiva de sancionar una conducta grave realizada por el amparado y proteger la unidad de la familia y el bien superior de los niños, opta por estos últimos:

[... 2) Hoy por hoy el amparado ha cumplido la pena que le impusieron los tribunales chilenos, por manera que obligarlo a dejar el país importa, de hecho, castigarlo por una conducta social y jurídicamente saneada, transgrediendo la máxima del non bis in ídem. 3) No se controvierte la circunstancia de encontrarse el amparado Sanji Kelemen en el país y ser padre de un menor nacido en Chile, por lo que, cualquiera sea el estado actual de esa experiencia familiar, es parecer del discrepante que surge una pugna entre el derecho del Estado a regular la residencia interna de extranjeros, por una parte, y los que el ordenamiento concibe en favor de la familia y, muy particularmente del niño, por la otra. En la disyuntiva, este juez opta por la protección de los segundos, siendo justamente y a la postre ésta la marca distintiva entre la cuerda de amparo motivo de esta vista, y la inicialmente recordada en esta resolución ${ }^{10}$.

Creemos que este voto es una muestra de las tensiones que encontramos en materia de extranjería y migración. En efecto, el Estado se encuentra en la disyuntiva entre sancionar ciertas

$9 \quad$ Corte Suprema. Caso Luis Loyola con DEM y otros. Sentencia de 9 de enero de 2013. Rol 66-2013, considerandos 6 y 7. En el mismo sentido: Corte Suprema. Caso Fali Leiva con DEM. Sentencia de 23 de enero de 2013. Rol 4002013.

10 Corte Suprema. Caso Sanji Kelemen con DEM. Sentencia de 8 de julio de 2013. Rol 4406-2013. Voto de minoría del juez Carlos Cerda, considerando 3. 
conductas a través de la expulsión y la protección de los derechos de los niños/as y la unidad familiar. Estimamos acertado el camino que tomó el Ministro Cerda, quien resuelve esta tensión centrado la atención en los derechos humanos por sobre otras consideraciones.

\section{Jurisprudencia en materia de nacionalidad y apatridia}

La acción de reclamación de nacionalidad consagrada en el artículo 12 de la Constitución Política ha sido la herramienta jurídica para enfrentar aquellos actos o resoluciones emanados del DEM que han desconocido la nacionalidad chilena a aquellos hijos e hijas de extranjeros que la autoridad ha calificado como transeúntes, generando una apatridia de facto. Cuando los casos han sido Ilevados ante la Corte Suprema, en casi todos los procesos se han acogido los reclamos, reconociéndose finalmente la nacionalidad chilena a aquellos hijos/as de extranjeros que han nacido en territorio nacional y que en el momento del alumbramiento sus progenitores se encontraban en situación migratoria irregular.

A pesar de las victorias prácticas, donde el objetivo es cumplido cuando el Estado se decide por reconocer la nacionalidad chilena a un individuo determinado, el contenido de los fallos (razonamiento judicial) no es contundente. En primer lugar, la Corte Suprema resuelve casos que involucran derechos fundamentales, reconocidos y garantizados por diversos tratados internacionales ratificados y hoy vigentes en Chile, invocando normas generales del Código Civil (artículos 58 y 59) y utilizando como herramienta de interpretación, las definiciones que consagra el Diccionario de la Real Academia Española (respecto a lo que debe entenderse como extranjero transeúnte); ejercicio de interpretación que no alcanza a satisfacer el estándar internacional que ha fijado la Corte Interamericana de Derechos Humanos (Corte IDH) en los casos de las Niñas Yean y Bosico ${ }^{11}$ y Castillo Petruzzi ${ }^{12}$, además de lo que ha indicado en las opiniones consultivas OC-4/84 ${ }^{13}$ y OC-18/03 ${ }^{14}$. En el mismo sentido, existe también un tímido control de convencionalidad por parte de los jueces nacionales en materia de nacionalidad.

Durante el año 2013, la Oficina de Derechos Humanos de la CAJ, patrocinó tres reclamos de nacionalidad, de los cuales dos fueron resueltos a favor de los reclamantes ${ }^{15}$.

En el primero de estos casos, la Corte Suprema señaló que: "[...] el criterio administrativo original para distinguir a extranjeros transeúntes de los que no lo son ha sido modificado, dejándose de considerar la permanencia continuada igual o superior a un año y prefiriéndose, en cambio, como elemento principal, el de la residencia, y en este contexto se estima indubitadamente transeúntes a los turistas y tripulantes ${ }^{\prime 16}$. Además, la Corte Suprema fundó la sentencia destacando

11 Corte IDH. Caso de las Niñas Yean y Bosico vs. República Dominicana. Sentencia de 8 de septiembre de 2005. Serie C No. 130.

12 Corte IDH. Caso Castillo Petruzzi y otros vs. Perú. Fondo, Reparaciones y Costas. Sentencia de 30 de mayo de 1999. Serie C No. 52.

Corte IDH. Propuesta de Modificación a la Constitución Política de Costa Rica Relacionada con la Naturalización. Opinión Consultiva OC-4/84 de 19 de enero de 1984. Serie A No. 4.

Corte IDH. Condición Jurídica y Derechos de los Migrantes Indocumentados. Opinión Consultiva OC-18/03 de 17 de septiembre de 2003. Serie A No. 18, en virtud del cual se extrae el principio de que el "estatus migratorio de una persona no se transmite a sus hijos".

En el último de ellos no fue necesario que se realizan alegatos, ya que un día antes de la audiencia, el DEM presentó un nuevo informe ante la Corte Suprema, acompañando un nuevo certificado de nacimiento en el que reconoció la nacionalidad chilena del menor afectado. administrativo original que definía a extranjeros transeúntes como aquellos que no podían acreditar un año de permanencia legal y continuada en el país, se contemplaba en la Orden de Servicio No. 4.946 de fecha 14 de julio de 1982, la cual fue reiterada en democracia mediante Circular DG No. 58/94 de fecha 25 de noviembre de 1994 del 
el ánimo de permanencia de la madre de la menor ${ }^{17}$. Asimismo, innovó al hacer mención expresa del artículo 20 del Pacto de San José de Costa Rica que consagra el derecho a la nacionalidad. Sin embargo, esta última apreciación no fue unánime en el máximo tribunal ${ }^{18}$.

Por su parte, en el segundo caso conocido por la Corte Suprema, destaca un nuevo argumento utilizado por el máximo tribunal. Interpretando el ánimo de residencia de los extranjeros, se reconoce el interés que desplegaron por largo tiempo los progenitores del reclamante para permanecer en territorio nacional, donde se incluye la solicitud de refugio, aunque fuere extemporánea, y así los califica como "residentes provisorios", concepto de creación jurisprudencial"

El presente acápite no podía omitir un singular caso que la Oficina de Derechos Humanos de la CAJ tuvo la oportunidad de tramitar ${ }^{20}$. El caso trataba de una persona nacida el año 1948 en Wilhelmshaven, ciudad ubicada en la ex República Federal de Alemania. Su padre era yugoslavo y su madre alemana. Al celebrar su matrimonio, antes del nacimiento del menor, esta última perdió su nacionalidad por contraer nupcias con una persona extranjera, según disponía la legislación alemana vigente hasta 1953. Producto de ello, la persona no adquirió nacionalidad alemana, ni tampoco la yugoslava (hoy inexistente).

Como corolario de los desastres de la Segunda Guerra, la familia decidió emigrar al continente americano. Arribaron a mediados de 1949 en calidad de refugiados al puerto de Valparaíso. Posteriormente, se trasladaron al sur del país, donde la persona realizaría sus estudios primarios, secundarios y superiores. Más tarde contraería matrimonio y tendría tres hijos chilenos. Luego de diversos intentos para regularizar su situación migratoria, en 1982 el Estado de Chile le otorgó permanencia definitiva, sin embargo, en la cédula de identidad para extranjeros que recibió del Estado chileno, no estaba determinada la nacionalidad de la persona.

Es así como la persona vivió una apatridia de hecho desde el momento de su nacimiento. A pesar de tener edad adulta, su nacionalidad no fue establecida en ninguna oportunidad ${ }^{21}$. Así las cosas, el año 2006, luego de que la persona fuese condenada por conducción en estado de ebriedad y como autor del delito de tráfico ilícito de estupefacientes, y que además cumpliese más de 6 años en prisión efectiva, el Ministerio del Interior dispuso su expulsión del país, in-

Servicio de Registro Civil e Identificación. El nuevo criterio ha ido cambiando paulatinamente desde la sentencia de 28 de diciembre de 2012, rol 6073-2009.

Corte Suprema. Sentencia de 11 de marzo de 2013. Rol 9168-2012, considerando 7.

18 Al respecto, los Ministros Sr. Valdés y Sra. Engem, consideraron innecesario recurrir a normas internacionales para resolver el asunto, toda vez que discurren en que las normas internas "brindan la solución adecuada y justa al problema planteado". En estos votos podemos apreciar una interpretación neutralizadora que, en palabras del jurista Frederic Sudre, "es una estrategia de evadir, eludir o de evitar, tendiente a neutralizar la interpretación del corpus iuris interamericano o de la Convención Europea de Derechos Humanos o la jurisprudencia de la Corte Interamericana de Derechos Humanos o del Tribunal Europeo de Derechos Humanos, creando, por una interpretación forzada del derecho nacional, una reescritura de la ley o una especie de mutación, una relación de adecuación entre el derecho interno y la norma interamericana o europea en su caso". Citado en: NOGUEIRA, Humberto (Coord.). Diálogo judicial multinivel y principios interpretativos favor persona y de proporcionalidad. Santiago: $\mathrm{CECOCH}$, Editorial Librotecnia, p. 40.

Corte Suprema. Sentencia de 29 de abril de 2013. Rol 300-2013, considerando 9.

Corte de Apelaciones de Santiago. Caso Jovan Savo con Ministerio del Interior y Seguridad Pública. Sentencia de 4 de julio de 2013. Rol 1008-2013.

21 Esta situación fue ratificada, por un lado con la desintegración de Yugoslavia (ya no podría adquirir dicha nacionalidad), y por otro, después de que la Oficina de Derechos Humanos de la Corporación de Asistencia Judicial enviara una misiva a la Bundesverwaltungsant (Oficina Federal de Administración Pública de Alemania), solicitando el pronunciamiento sobre la nacionalidad de la persona. La respuesta de la actual República Federal Alemana fue que la persona no era nacional alemán. 
vocando la causal del artículo 15 No. 2 en relación con el artículo 17 del D.L No. 1094. Sin embargo, la expulsión nunca fue ejecutada.

El caso tenía un especial interés teórico y humano, debido a que la condición de apátrida tiene importantes diferencias conceptuales con la situación de ser extranjero. Ello trae aparejada importantes consecuencias jurídicas y prácticas para una expulsión. Así, las preguntas de ¿cómo se efectuaría la expulsión?, o ¿a qué lugar se expulsaría la persona?, parecían tan obvias como insalvables. Probablemente estas mismas dudas hacían que la administración no supiera como dar ejecución a un acto que ella misma había dictado. En el aspecto teórico, por su parte, tanto para efectos del ordenamiento jurídico interno de Chile como para el Derecho Internacional, la persona apátrida no es un extranjero. Ello a partir de una interpretación del sentido natural y obvio de las palabras: un extranjero es aquél que tiene nacionalidad de un Estado pero se encuentra temporáneamente fuera de él ${ }^{22}$. El apátrida, a diferencia del extranjero, es aquella persona que ningún Estado reconoce como nacional suyo ${ }^{23}$. En consecuencia, "extranjero" y "apátrida" no son sinónimos. A partir de esta interpretación no cabe aplicar la legislación de extranjería a los apátridas, menos aun cuando es el mismo D.L. No. 1094 el que, en su artículo 1, determina su alcance de forma expresa ${ }^{24}$. Tratar como conceptos equivalentes al apátrida y al extranjero, sería tan absurdo como aplicar a un refugiado las normas concernientes a los turistas, o resolver materias de familia con legislación mercantil. Así, estamos en presencia de calidades migratorias diferentes, cada una con normas jurídicas propias.

Para abordar este caso, además de este argumento, se incluyeron aquellos relativos a los vínculos de familia y la puesta en duda de la vigencia del acto administrativo debido al tiempo prolongado transcurrido sin que la administración lo haya ejecutado ${ }^{25}$.

Así las cosas, con fecha 10 de junio de 2013, se interpuso una acción constitucional de amparo en favor de la persona apátrida, con la finalidad de dejar sin efecto la orden de expulsión que pesaba en su contra, acción que fue acogida por la Corte de Apelaciones de Santiago.

A pesar de que la Corte de Apelaciones no se pronunció sobre uno de los principales fundamentos de la acción -esto es, respecto a la situación de apatridia y la inaplicación del D.L. No.1094-, sorprendió con un argumento novedoso, haciendo referencia a la denominada "teoría del decaimiento del acto administrativo":

\footnotetext{
Que el control de legalidad que este Tribunal está llamado a ejercer en el plano de la jurisdicción conservadora y cautelar de libertades personales obliga a evaluar si subsisten o no en la actualidad los presupuestos de hecho llamados a dar racionalidad al acto administrativo que, quizá seis años atrás, pudo tener algún fundamento. De no concurrir estos últimos, el acto administrativo incurre en decaimiento, por lo cual es posible, racional y justo dejarlos sin efecto, más aún cuando sus consecuencias recaen en la esencia de la libertad de las personas, como es manifiesto que ocurre en la especie [...]
}

[...] Siendo jurídicamente admisibles ambas posturas, en parecer de estos sentenciadores, la

22 De acuerdo a la Real Academia Española, entre las excepciones de extranjero, define: "1. Que es o viene de país de otra soberanía. 2. Natural de una nación con respecto a los naturales de cualquier otra". Claramente estas definiciones no coinciden con la de apátrida.

23 Artículo 1 Convención sobre el Estatuto de los Apátridas de 1954.

24 Artículo 1 D.L. No. 1094/75: "El ingreso al país, la residencia, la permanencia definitiva, el egreso, el reingreso, la expulsión y el control de los extranjeros se regirán por el presente decreto ley" (el subrayado es nuestro).

25 Habían transcurrido más de 6 años desde la dictación y notificación del acto, sin que existiera alguna gestión de la autoridad administrativa tendiente a ejecutarlo. 
tardanza de a lo menos seis años en hacer cumplir el acto de expulsión que pesaba en contra del recurrente, unida a las circunstancias personales y familiares del afectado, han llevado naturalmente a tener por establecido que el fundamento de hecho que se tuvo a la vista al ordenarse la expulsión de éste del territorio nacional ha desaparecido por completo ${ }^{26}$.

Para finalizar este acápite quisiéramos insistir en la diferencia conceptual y jurídica entre un "extranjero" y un "apátrida". Hablamos de calidades diferentes, con efectos jurídicos distintos. En este sentido, nos parece importante que el Estado de Chile firme, ratifique y de plena aplicación a la Convención sobre el Estatuto de los Apátridas de 1954 y la Convención para Reducir los Casos de Apatridia de 1961, lo que daría un marco normativo especial aplicable a los apátridas. Hoy en Chile no existe legislación específica que se haga cargo de la situación de los apátridas y resguarde el pleno ejercicio de derechos de personas que tienen dicha calidad. Lo que sí es claro, es que no existe autoridad facultada expresamente por ley para afectar la libertad ambulatoria de un apátrida mediante una orden de expulsión ${ }^{27}$.

\section{Jurisprudencia en materia de privaciones de libertad: el "Caso Cuartel Borgoño"}

Con fecha 25 de febrero de 2013, luego de una visita realizada a las dependencias de la Brigada de Investigación Criminal de Santiago de la Policía de Investigaciones, también conocido como el "Cuartel Borgoño", pudimos constatar que los extranjeros en situación migratoria irregular eran sometidos a privación de libertad, sin que dicha privación fuese controlada por juez alguno $^{28}$. La Policía de Investigaciones manifestó que las personas no estaban detenidas, sino en "custodia" hasta que se realizara la expulsión, por lo que no cabía a su respecto audiencia ante un juez para un control de detención.

Ante esta situación, se presentó una acción constitucional de amparo ante la Corte de Apelaciones de Santiago. Resulta particularmente interesante destacar que esta sentencia incorpora un concepto relevante, al calificar a los migrantes indocumentados como integrantes de un "grupo en situación de vulnerabilidad", tal como lo había indicado la Corte IDH en su Opinión Consultiva sobre la "Condición Jurídica y Derecho de los Migrantes Indocumentados"29. Así, la Corte de Apelaciones indicó:

En un mundo 'globalizado', con grandes consensos sobre principios y reglas de convivencia, la realidad da cuenta que el fenómeno de la migración ha alcanzado a estas alturas grados de intensidad y de universalidad tales, que llega a ser cierto que no existe país en el mundo que no experimente el ingreso de personas extranjeras. Entre otras derivaciones, ello trae consigo que el poder estatal para gestionar los movimientos migratorios no puede prescindir de la consideración de derechos fundamentales e inalienables, que derivan de la condición de ser humano, protegidos tanto por los ordenamientos internos como por los diversos instrumentos de Derecho Internacional. En lo que atañe a nuestro Derecho, cabe recordar que el catálogo 'de primera generación', contemplado en el artículo 19 de la Constitución Política de la Repú-

26 Corte de Apelaciones de Santiago. Caso Jovan Savo con Ministerio del Interior y Seguridad Pública, op.cit, considerandos 4 y 5 .

27 Como se dijo, el D.L. No.1094/75, es solo aplicable a los "extranjeros".

Algunos de los detenidos llevaban varios días o semanas en esa situación.

"Generalmente los migrantes se encuentran en una situación de vulnerabilidad como sujetos de derechos humanos, en una condición individual de ausencia o diferencia de poder con respecto a los no-migrantes (nacionales o residentes). Esta condición de vulnerabilidad tiene una dimensión ideológica y se presenta en un contexto histórico que es distinto para cada Estado, y es mantenida por situaciones de jure (desigualdades entre nacionales y extranjeros en las leyes) y de facto (desigualdades estructurales). Esta situación conduce al establecimiento de diferencias en el acceso de unos y otros a los recursos públicos administrados por el Estado". Corte IDH. Condición Jurídica y Derechos de los Migrantes Indocumentados, op.cit, párr.112. 
blica, se proclama como asegurado 'a todas las personas', sin distinción alguna, de modo que el imperativo de respeto y promoción de tales derechos esenciales, en los términos a que alude el artículo $5^{\circ}$ de la Carta Fundamental, se hace extensivo a los no nacionales que se encuentran en el territorio de Chile. Ese deber de respeto y promoción adquiere ribetes especiales cuando se trata de extranjeros, en la medida que ellos se encuentran en una indudable situación de vulnerabilidad, de momento que carecen de redes de apoyo familiares y de proximidad, precisamente porque se hallan en un país que no es propio. En un contexto como el reseñado, existen ciertos derechos particularmente atingentes al caso y, entre ellos, por cierto, el derecho a la libertad personal, en todas sus dimensiones ${ }^{30}$.

Respecto de los plazos de detención para efectos de expulsiones, la sentencia señala que este no puede exceder las 24 horas $^{31}$. Además, previa inspección personal del tribunal, la sentencia califica las condiciones de la detención como "inadecuadas e indignas"

Además de la importancia de lo resuelto, destacamos que la Corte de Apelaciones haya incorporado el concepto de "grupo en situación de vulnerabilidad" a nuestra jurisprudencia en materia de inmigración, pues esto implica que el Estado debe tomar medidas especiales para garantizar los derechos humanos de las personas pertenecientes a dichos grupos. Además, aclara que no cabe realizar una distinción entre estar "detenido" y "bajo custodia", por lo que se hacen aplicables a ambas situaciones los mismos requisitos en cuanto a los plazos máximos y al necesario control jurisdiccional.

\section{Jurisprudencia del Tribunal Constitucional: inaplicabilidad del artículo 13 del D.L. No. 1094/75}

El Tribunal Constitucional, conociendo sobre un requerimiento de inaplicabilidad por inconstitucionalidad deducido durante la tramitación de un recurso de protección, debió analizar si la aplicación del artículo 13 del D.L. No.1094, que otorga al Ministerio del Interior "facultades discrecionales" para rechazar visados y dictar órdenes de abandono bajo el criterio de "utilidad y conveniencia para el país", tendría o no efectos contrarios a la Constitución en un caso concreto $^{33}$. En el recurso en comento, el caso concreto consistía en el rechazo de visa y posterior orden de abandono, dictada en virtud del mencionado criterio de "utilidad y conveniencia", en contra de una persona de nacionalidad haitiana.

Esta sentencia tiene particular interés, no solo por ser la primera del Tribunal Constitucional que se pronuncia sobre preceptos legales del D.L. No.1094, sino además porque a través de su razonamiento, el Tribunal arriba a importantes conclusiones. Estas son:

- Toda persona tiene derecho a migrar ${ }^{34}$.

30 Corte de Apelaciones de Santiago. Caso Cuartel Borgoño. Sentencia de 9 de marzo de 2013. Rol 351-2013, considerando 3. El destacado es nuestro.

31 Ibídem, considerando 9.

32 Ibídem, considerando 10. En la parte resolutiva, la Corte de Apelaciones, ordenó: "1) la Policía de Investigaciones de Chile deberá poner inmediatamente en libertad a los detenidos; 2) remisión de los autos al Ministerio Público, por estimarse que los hechos pudieran revestir los caracteres de delito y; 3) envío de copia de la causa al Ministro del Interior y al Director de la Policía de Investigaciones, para los efectos disciplinarios a los que pudiera haber lugar y a objeto que dichas autoridades estudien la adopción de las medidas, providencias o procedimientos encaminados a evitar o precaver que, en lo sucesivo, puedan reiterarse situaciones como las evidenciadas en este caso". Respecto a este último punto, con fecha 28 de marzo de 2013, el Ministerio del Interior y Seguridad Pública dio a conocer un nuevo protocolo de expulsiones.

33 Tribunal Constitucional. Requerimiento de inaplicabilidad por inconstitucionalidad del D.L No.1094, op.cit. Ibídem, considerando 10. 
- El artículo 13 del D.L. No. 1094 (facultades discrecionales bajo criterios de utilidad o conveniencia) "es una norma preconstitucional que admite masivas vulneraciones de derechos". El tribunal sostiene además que "esta potestad del Ministerio del Interior está sujeta a límites materiales que provienen desde la Constitución, el Derecho Internacional y, especialmente, desde el derecho internacional de los derechos humanos" ${ }^{\prime 35}$.

- La Constitución Política no autoriza ni realiza ninguna distinción que permita un tratamiento diferente entre nacionales y extranjeros en el ejercicio del derecho fundamental de libertad ambulatoria contenido en el artículo 19 No. 7 letra a) de la Carta Fundamental ${ }^{36}$. Ello redunda en que toda persona que ingrese regularmente al país goza de este derecho constitucional como si fuera chileno ${ }^{37}$.

- El inmigrante que ha ingresado regular al país ha de recibir un tratamiento jurídico igualitario al de un nacional, de conformidad a los tratados internacionales de derechos humanos y la Constitución. El derecho es a residir y permanecer, lo que importa el derecho a regularizar su estadía y a ser tratado de la misma forma que los nacionales ${ }^{38}$.

- A partir de este caso el Tribunal Constitucional construye una doctrina que, a su juicio "altera el entendimiento que ha existido acerca de la potestad discrecional del Ministerio del Interior para otorgar y rechazar visados [...] lo que lleva a que exista la necesidad de establecer reglas tasadas para disponer el rechazo de un visado en el país. Estas reglas se configuran por el nuevo estándar que se deriva de las disposiciones de derecho internacional de los derechos humanos, de normas legales que desarrollan derechos constitucionales y del propio texto constitucional" 39 .

- Complementa lo concluido, indicando los elementos que constituyen el nuevo estándar que tiene la administración para abordar casos relacionados con personas migrantes: "Que en el ejercicio de estas potestades el Ministerio del Interior tiene un nuevo estándar. En esa virtud, no podrá discriminar entre extranjeros, artículo 2 del Pacto Internacional de Derechos Civiles y Políticos, en relación con los artículos 25 y 13 de dicho Pacto, respectivamente, y artículo $2^{\circ}$ de la Ley 20.609); deberá tener en cuenta las relaciones familiares, especialmente el principio de reagrupación familiar (artículo 16 de la Declaración Universal de Derechos Humanos, 10 y 11 del Pacto Internacional de Derechos Económicos, Sociales y Culturales, 10.1 de la Convención de Derechos del Niño y 12, 13 y 23 del Pacto Internacional de Derechos Civiles y Políticos); deberá atender a las persecuciones por motivos políticos o aquellas que pongan en riesgo la vida y la integridad física y síquica del extranjero (artículo 22.8 de la Convención Americana de Derechos Humanos); deberá reconocer los derechos constitucionales del extranjero que haya ingresado legalmente al país y cuya situación de residencia temporal o definitiva se encuentra en una fase de regularización (artículo 12.3 del Pacto Internacional de Derechos Civiles y Políticos); y, finalmente, que el propio artículo 19 No. 7 no apodera al Estado a configurar reglas que diferencien radicalmente en el ejercicio del derecho de circulación y de residencia del extranjero, salvo su estricto apego al cumplimiento de los requisitos legales de general aplicabilidad a toda persona" ${ }^{40}$.

\footnotetext{
Ibídem, considerando 7.

lbídem, considerando 35.

Ibídem, considerando 38.

Ibídem, considerando 42.

Ibídem, considerando 49.

lbídem, considerando 50.
} 
Este último considerando del Tribunal Constitucional es una de los aspectos más destacables de la sentencia en comento, pues fija un estándar para abordar la situación de las personas migrantes, desde el complejo conjunto de normas del DIDH, armonizándolas con la normativa interna.

\section{Conclusiones}

En el análisis jurisprudencial que hemos realizado queda de manifiesto que los tribunales superiores de justicia en Chile han iniciado un correcto camino para garantizar los derechos fundamentales de las personas migrantes. En efecto, los fallos incluyen e invocan normas de DIDH, dando una aplicación preferente a la Convención Americana sobre Derechos Humanos y a la Convención sobre los Derechos del Niño, abordando la problemática considerando que las personas migrantes forman parte de un "grupo en situación de vulnerabilidad", tal como lo ha indicado la Corte IDH.

También podemos apreciar que las sentencias estudiadas analizan la razonabilidad y proporcionalidad de las sanciones dictadas por la administración -en especial órdenes de abandono y expulsiones-, exigiendo la valoración de circunstancias familiares y personales concurrentes al momento de examinar la legalidad y razonabilidad de las decisiones.

Se vislumbra además la realización de un exhaustivo examen de legalidad ante privaciones de libertad de los extranjeros afectados por órdenes de expulsión o abandono.

Por otra parte, podemos sostener que no basta con que la autoridad invoque sus facultades discrecionales para justificar una expulsión de un padre o una madre cuando esta perjudica el bien superior del niño y el principio de la unidad familiar. Tampoco dicha discrecionalidad alcanza para calificar de inconveniente o inútil la permanencia de un extranjero en el país. Una calificación de este tipo tendría efectos contrarios a los preceptos constitucionales.

Finalmente, y de acuerdo a la jurisprudencia constitucional, podemos sostener que el derecho a residir y a migrar, alcanza no solo a los nacionales, sino a todas las personas, sin discriminación alguna. 